\title{
A CHRNA5 Smoking Risk Variant Decreases the Aversive Effects of Nicotine in Humans
}

\author{
Kevin P Jensen ${ }^{*, 1,2}$, Elise E DeVito ${ }^{1,2}$, Aryeh I Herman ${ }^{1,2}$, Gerald W Valentine ${ }^{1,2}$, Joel Gelernter ${ }^{1,2,3,4}$ and \\ Mehmet Sofuoglu ${ }^{1,2}$
}

'Department of Psychiatry, Yale University School of Medicine, New Haven, CT, USA; ${ }^{2}$ VA Connecticut Healthcare System, West Haven, CT, USA;

${ }^{3}$ Department of Genetics, Yale University School of Medicine, New Haven, CT, USA; ${ }^{4}$ Department of Neurobiology, Yale University School of

Medicine, New Haven, CT, USA

\begin{abstract}
Genome-wide association studies have implicated the CHRNA5-CHRNA3-CHRNB4 gene cluster in risk for heavy smoking and several smoking-related disorders. The heavy smoking risk allele might reduce the aversive effects of nicotine, but this hypothesis has not been tested in humans. We evaluated the effects of a candidate causal variant in CHRNA5, rs 16969968, on the acute response to nicotine in European American (EA) and African American (AA) smokers ( $n=192 ; 50 \%$ AA; 73\% male). Following overnight abstinence from nicotine, participants completed a protocol that included an intravenous (IV) dose of saline and two escalating IV doses of nicotine. The outcomes evaluated were the aversive, pleasurable, and stimulatory ratings of nicotine's effects, cardiovascular reactivity to nicotine, withdrawal severity, and cognitive performance before and after the nicotine administration session. The heavy smoking risk allele ( $\mathrm{rs}$ 16969968*A; frequency $=28 \%(E A)$ and 6\% (AA)) was associated with lower ratings of aversive effects $\left(P<5 \times 10^{-8}\right)$ with marked specificity. This effect was evident in EA and AA subjects analyzed as separate groups and was most robust at the highest nicotine dose. Rsl6969968*A was also associated with greater improvement on a measure of cognitive control (Stroop Task) following nicotine administration. These findings support differential aversive response to nicotine as one likely mechanism for the association of CHRNA5-CHRNA3-CHRNB4 with heavy smoking.

Neuropsychopharmacology (2015) 40, 28I3-282I; doi: I0.1038/npp.20I5.131; published online 3 June 2015
\end{abstract}

\section{INTRODUCTION}

Nicotine dependence (ND) is a multifactorial disorder associated with high rates of morbidity and mortality. The estimated heritability for ND is about 0.59 in men and 0.46 in women ( $\mathrm{Li}$ et al, 2003), indicating significant genetic contributions. Studies on the genetics of ND have provided important insight into the molecular mechanisms underlying $\mathrm{ND}$ and several associated disorders, such as heavy smoking and lung cancer. Variants encoded within the CHRNA5CHRNA3-CHRNB4 gene cluster on chromosome 15 are strong candidates for ND risk, the severity of ND measured by Fagerström Test for Nicotine Dependence scores, the number of cigarettes smoked per day, as well as the risk for lung cancer, chronic obstructive pulmonary disease, and peripheral vascular disease (Amos et al, 2008; Berrettini et al, 2008; Bierut et al, 2007; Bierut et al, 2008; Chen et al, 2012; Chen et al, 2009; Gelernter et al, 2015; Hansen et al, 2010; Hung et al, 2008; Li et al, 2010; Lips et al, 2010; Liu et al, 2010; Saccone et al, 2010; Saccone et al, 2007; Sarginson et al,

\footnotetext{
*Correspondence: Dr KP Jensen, Department of Psychiatry, Yale University School of Medicine, VA Connecticut Healthcare System, 950 Campbell Avenue, West Haven, CT 06516, USA,

E-mail: kevin.jensen@yale.edu

Received 4 February 2015; revised 16 March 2015; accepted 16 April 2015; accepted article preview online 7 May 2015
}

2011; Sherva et al, 2010; Spitz et al, 2008; Thorgeirsson et al, 2008; Tobacco and Genetics Consortium, 2010; Wang et al, 2009).

A highly conserved non-synonymous SNP, rs16969968 ( $\mathrm{G}>\mathrm{A}$; amino acid $398 \mathrm{D}>\mathrm{N}$ ), in the CHRNA5 gene, which encodes the $\alpha 5$ subunit of nicotinic acetylcholine receptors (nAChR), apparently mediates some of the risk effects associated with the CHRNA5-CHRNA3-CHRNB4 gene cluster (Saccone et al, 2007). This hypothesis is supported by large GWAS meta-analyses and in vitro studies that have characterized the function of $398 \mathrm{D}>\mathrm{N}$ and behavioral studies of $\alpha 5$ in animal models (Bailey et al, 2010; Bierut et al, 2008; Fowler et al, 2011; Frahm et al, 2011; Jackson et al, 2010; Kuryatov et al, 2011; Saccone et al, 2010; Tammimaki et al, 2012; Tobacco and Genetics Consortium, 2010). The CHRNA5 risk allele, rs $16969968^{\star} \mathrm{A}(398 \mathrm{~N})$, encodes a protein that forms nACh receptors with lower activity in several in vitro paradigms (Bierut et al, 2008; Kuryatov et al, 2011). In a study with the $(\alpha 4 \beta 2) \alpha 5$ nAChR-transfected HEK293 cells, nAChR subunits containing the $\alpha 5$ risk allele $(398 \mathrm{~N})$ had twofold lower maximal response when challenged with epibatidine, a nicotinic agonist, compared with the $(\alpha 4 \beta 2) \alpha 5$ nAChRs that contained the $\alpha 5$ protective allele (398D) (Bierut et al, 2008). Further, when the risk allele of $\alpha 5$ was incorporated into $(\alpha 4 \beta 2)^{*} \mathrm{nAChRs}$ expressed in Xenopus oocytes, there was an increase in short-term desensitization 
and lower calcium permeability relative to $(\alpha 4 \beta 2)^{\star} \mathrm{nAChRs}$ that contained the protective allele (Kuryatov et al, 2011). These functional differences for $398 \mathrm{D}>\mathrm{N}$ were observed for ( $\alpha 4 \beta 2) \alpha 5$, the $\alpha 5 \mathrm{nAChR}$ subtype that is most common in the brain, and not observed for $\alpha 5 \mathrm{nAChR}$ subtypes that are rare in the brain but common in the periphery (Kuryatov et al, 2011).

The function of $\alpha 5$ as evaluated in animal models is consistent with and relevant to nicotine's cognitive-enhancing and subjective drug effects. Under highly demanding conditions, knockout $\alpha 5$ mice have reduced cognitive performance in attention tasks compared with the wild-type mice; yet under these demanding conditions, nicotine negatively affected the performance of wild-type mice but not $\alpha 5$ knockouts (Bailey et al, 2010). At high doses of nicotine but not at low doses, mice lacking the $\alpha 5$ subunit have reduced aversive and elevated reward responses to nicotine relative to wild-type animals (Jackson et al, 2010). Although the $\alpha 5$ subunit is expressed widely in the central and peripheral nervous system as part of various nAChRs, including $\alpha 4 \beta 2^{*}, \alpha 3 \beta 2^{*}$, or $\alpha 3 \beta 4^{\star}$, rodent studies suggest that $\alpha 5$ expressed in the medial habenula may be most relevant to the risk effects marked by rs16969968 (Fowler et al, 2011; Frahm et al, 2011). Fowler et al (2011) showed that viral-mediated expression of $\alpha 5$ specifically in the medial habenula of $\alpha 5$ knockouts is sufficient to restore the aversive effects of nicotine to wild-type levels. In contrast, RNAi-mediated knockdown of $\alpha 5$ specifically in habenulo-interpeduncular tract cells of wild-type animals induced a nicotine-aversion phenotype that was similar to the constitutive $\alpha 5$ knockouts. These important studies highlight the critical role of $\alpha 5$ in regulating the aversive effects of nicotine. Based on these studies, it has been inferred that the low activity form of $\alpha 5$, encoded by rs $16969968^{\star} \mathrm{A}$, renders individuals less sensitive to the aversive effect of nicotine. Although an intriguing mechanism to explain the risk associated with $\mathrm{rs} 16969968^{\star} \mathrm{A}$, there is limited direct evidence from human studies to support this type of specific behavioral effect of rs16969968 on aversion to nicotine or the cognitive-enhancing effects of nicotine.

Characterizing the behavioral effects of rs16969968 in humans could lead to significant health benefits and increase our fundamental understanding of a well-established behavioral genetics effect. This could be established by measuring subjective and objective responses to nicotine in humans in a laboratory setting, but cigarette smoking is a complex behavior and the amount of nicotine delivered via smoking can be highly variable (Hatsukami et al, 2006; Hoffmann and Wynder, 1986). Assessing the relevant properties of rs16969968 in humans requires a non-variable nicotine delivery system. Among pure nicotine delivery systems, delivery via patch is slow and does not produce subjective rewarding effects. Faster nicotine delivery systems, including nicotine gum and nasal spray, produce minimal or no drug 'liking' effects and are not preferred over placebo by smokers in self-administration procedures (Perkins, 1996; Schneider et al, 2005; Schuh et al, 1997). We have developed an intravenous (IV) nicotine administration paradigm to evaluate accurately and precisely responses to nicotine that are relevant to smoking behavior (Sofuoglu et al, 2003; Sofuoglu et al, 2005; Sofuoglu et al, 2006). The advantages of this IV paradigm are precise nicotine dosing and a rapid nicotine delivery that is comparable to the bolus effect of smoking. This IV nicotine paradigm produces robust 'pleasurable', 'stimulatory', and 'aversive' subjective effects that are similar to cigarette smoking. Unlike other pure nicotine delivery systems, this paradigm is reinforcing and is self-administered by male and female smokers (Sofuoglu et al, 2008). This paradigm also, similar to cigarette smoking, attenuates symptoms of nicotine withdrawal and craving to smoke and improves cognitive performance in abstinent smokers (DeVito et al, 2013; Herman et al, 2013; Sofuoglu et al, 2012).

Here we used this laboratory paradigm to evaluate the effects of rs16969968 in European American (EA; $N=96$ ) and African American (AA; $N=96)$ smokers. The dosedependent response to nicotine was evaluated for multiple outcomes, including the subjective ratings of 'aversive', 'pleasurable', and 'stimulatory' effects. Cardiovascular response to nicotine, symptoms of nicotine withdrawal, and effects on cognitive performance were also evaluated.

\section{MATERIALS AND METHODS}

\section{Subjects and Genotyping}

One hundred and ninety-two non-treatment-seeking EA (50\%) and AA (50\%) smokers were recruited from the New Haven, Connecticut area for a nicotine laboratory study. All provided written informed consent before participating in the study, and subjects were paid for their participation. Institutional review boards at Yale University and the VA Connecticut Healthcare System approved the study. Seventythree percent of subjects were male, and the mean age was $36.3(\mathrm{SD}=8.9)$ years. Some subjects from this population have been included in previous studies (DeVito et al, 2013; Herman et al, 2013; Jensen et al, 2014; Sofuoglu et al, 2012). All subjects reported smoking 10-25 cigarettes/day for the past year, had expired carbon monoxide levels of $\geqslant 10$ parts per million at initial screening, and had no major medical problems as determined by a self-report, a physician's health check, and laboratory testing. Subjects were evaluated with the Structured Clinical Interview for DSM-IV (First et al, 1996) and subjects who met criteria for a current psychiatric disorder, including dependence on alcohol or drugs (other than nicotine), were excluded from the study. A urine drug screen confirmed abstinence from drugs other than nicotine. Individuals on psychotropic medication or who were pregnant or breastfeeding were also excluded. DNA was extracted from whole blood using a commercial kit (PureGene; Gentra, Minneapolis, MN, USA). Subjects were genotyped for CHRNA5 rs16969968 with a 2- $\mu$ l TaqMan allelic discrimination assay (Applied Biosystems, Foster City, CA, USA). The subjects were assigned to EA or AA group based on a previously described genetic marker method (Herman et al, 2013; Yang et al, 2005) or based on self-report.

\section{Laboratory Procedure and Assessments}

Experimental sessions started at 0800 hours following an overnight abstinence from smoking, confirmed by expired carbon monoxide levels $<10$ parts per million and plasma nicotine levels $<4 \mathrm{ng} / \mathrm{ml}$. The study procedure has been described in detail elsewhere (Herman et al, 2013; Sofuoglu et al, 2012) At baseline, after IV lines were established, 
subjects completed the Minnesota Nicotine Withdrawal Scale (MNWS) (Hughes and Hatsukami, 1986), the Brief Questionnaire of Smoking Urges (BQSU) (Tiffany and Drobes, 1991), and the Positive and Negative Affect Schedule (PANAS) (Watson et al, 1988). Subjects were then administered an IV dose of saline, followed by two escalating doses of nicotine $(0.5 \mathrm{mg}$ per $70 \mathrm{~kg}$ of body weight and $1 \mathrm{mg}$ per $70 \mathrm{~kg}$ of body weight) in uniform order to avoid nicotine carryover into the saline dose. Nicotine was infused over $30 \mathrm{~s}$ IV via a forearm catheter. Each infusion was separated by $30 \mathrm{~min}$. During the experimental session, the subjective effects of nicotine (and saline placebo) were assessed with the Drug Effects Questionnaire (DEQ) and blood pressure (systolic and diastolic) and heart rate (HR) were monitored. Each individual DEQ response was rated on a visual $100-\mathrm{mm}$ scale that was then converted to a rating from 1 to 10 . Approximately $20 \mathrm{~min}$ after the final dose of nicotine, subjects repeated the MNWS, BQSU, and PANAS. Two subjects (of 192) did not complete the MNWS and 6 did not complete the BQSU and PANAS.

The Stroop Task, The Running Memory Continuous Performance Task (CPT) and The Mathematical Processing Task (MPT) were performed at baseline and at the end of the session. This computer-based cognitive battery from Automated Neuropsychological Assessment Metrics (Reeves et al, 2007) has been described previously in detail for this paradigm (DeVito et al, 2013). One hundred and eighty-four subjects completed the cognitive assessments. The outcome analyzed for each cognitive task was the throughput score, a summary measure computed from the number of correct responses within the allotted time.

Plasma nicotine, cotinine, and 3'-hydroxycotinine levels prior to nicotine infusion were determined using HPLC interfaced with tandem mass spectrometry (LC/MS/MS) with deuterium-labeled internal standards, as previously described (Dempsey et al, 2004; Sofuoglu et al, 2012).

\section{Data Analysis}

Data were analyzed with linear mixed models using the JMP Pro (v10.0.0) software (SAS Institute). The DEQ and cardiac response models included as independent variables the following fixed effects: rs16969968 (grouped as A carrier vs GG), age, sex, race (EA or AA), IV dose (saline, $0.5 \mathrm{mg}$ nicotine and $1 \mathrm{mg}$ nicotine per $70 \mathrm{~kg}$ body weight), minute post-IV infusion, the interaction of dose with rs16969968, the interaction of minute post-IV infusion with rs16969968, the interaction of minute post-IV infusion with dose, and the interaction of minute post-IV infusion with dose and rs16969968. Subject was included in the linear mixed model as a random effect. Additive genetic models were also used as indicated in the Results section, with copies of the minor allele coded as 0,1 , and 2 for GG, AG, and AA genotype groups, respectively. Based on prior work indicating that the responses to nine DEQ items were correlated, we clustered nine responses into three domains representing aversive, pleasurable, and stimulatory effects (Morean et al, 2013). The average response for 'feel anxious', 'feel down', and 'feel bad' formed the aversive domain; the average response for 'like', 'feel good', and 'want more' formed the pleasurable domain; and the average response for 'feel stimulated', 'feel effects', and 'feel high' formed the stimulatory domain. The change in response to nicotine relative to saline for each drug effect domain (shown in Figure 1) was calculated by subtracting the value of the saline condition at $1,3,5,8$, and $10 \mathrm{~min}$ postinfusion from the corresponding value during the nicotine conditions for each individual, and the mean value of the five time points at each nicotine dose is reported. MNWS, PANAS, BQSU, ST, CPT, and MPT analysis models included the following fixed effects: rs16969968 (grouped as A carrier vs GG), age, sex, race (EA or AA), time point (baseline $v s$ end of session), and the interaction of time point with rs16969968, and included subject as a random effect. Additional covariates included in post-hoc analyses are described in the text.

\section{RESULTS}

\section{Demographic and Smoking-Related Characteristics}

Rs16969968 genotypes for EA and AA subjects are shown in Table 1. The genotype counts for the EA and AA samples did not deviate from Hardy-Weinberg expectations. Smokingrelated characteristics for the EA and AA subjects and for the rs16969968 genotype groups (A carrier vs GG) are shown in Table 2. rs16969968 was not associated with any baseline smoking-related characteristic.

\section{CHRNA5 rs16969968*A Moderates the Aversive Effects of Acute Nicotine}

Nicotine increased the ratings of stimulatory effects (main effect for dose: $\left.\mathrm{F}_{(2,3025)}=105.8, P<0.01\right)$ and pleasurable effects (main effect for dose: $\mathrm{F}_{(2,3025)}=124.7, P<0.01$ ), but not aversive effects (main effect for dose: $\mathrm{F}_{(2,3025)}=1.85$, $P=0.16$ ). Relative to $\mathrm{rs} 16969968^{\star} \mathrm{G}$ homozygotes, the aversive effects of IV-administered nicotine were blunted for subjects with one copy of rs16969968*A (Figure 1; dose-bygroup interaction: $\left.\mathrm{F}_{(2,3025)}=20.49, P<5 \times 10^{-8}\right)$. rs16969968 genotype differences in the aversive response to nicotine were evident when EA and AA subjects were analyzed as separate groups (EA dose-by-group interaction: $\mathrm{F}_{(2,1507)}=$ 17.75, $P<5 \times 10^{-8}$; AA dose-by-group interaction: $\mathrm{F}_{(2,1506)}=$ 3.7, $P<5 \times 10^{-2}$; Supplementary Figure S1) and when the analysis model included three genotype groups (coded additively, rather than A carriers $v s$ GG) (dose-by-group interaction: $\left.\mathrm{F}_{(2,3024)}=21.7, P<5 \times 10^{-8}\right)$. The effect remained robust in post-hoc analyses that controlled for smoking intensity (cigarettes smoked per day), as well as baseline nicotine metabolite ratio and cotinine and 3-hydroxycotinine levels. The essence of this effect is captured in the bar graph of Figure 1a, which shows the change in the ratings of aversive effects after IV nicotine relative to IV saline for each genotype group. The aversive ratings increased in response to nicotine for the GG group, whereas aversive ratings decrease for $\mathrm{rs} 16969968^{\star} \mathrm{A}$ carriers. In contrast to the pronounced differences in ratings of aversive effects in response to nicotine, there were no compelling differences in ratings of pleasurable effects (dose-by-group interaction: $\left.\mathrm{F}_{(2,3025)}=2.1, P=0.12\right)$ or ratings of stimulatory effects (dose-by-group interaction: $\mathrm{F}_{(2,3025)}=0.24, \quad P=0.79$ ) for

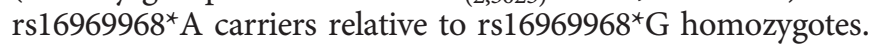



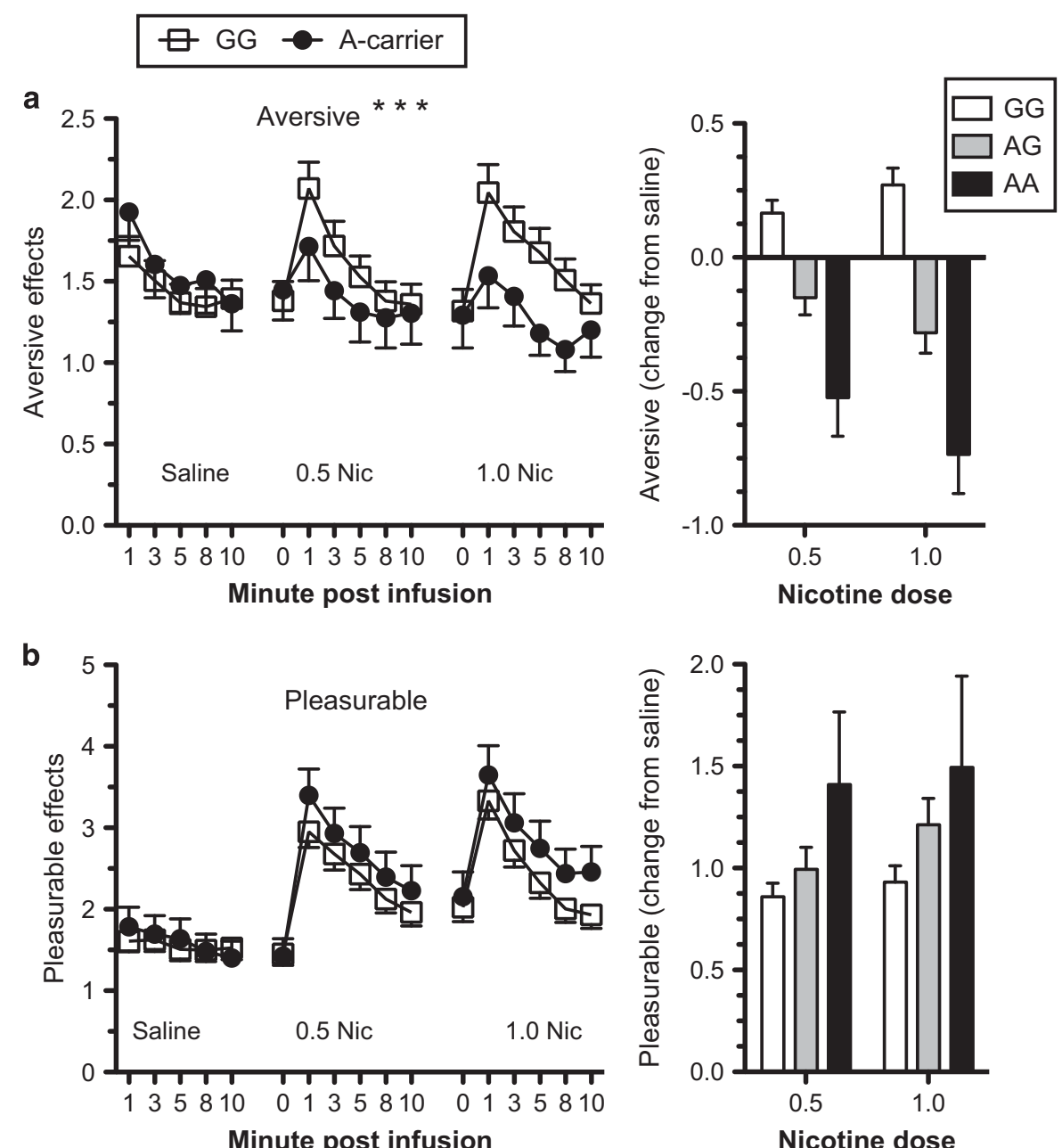

Nicotine dose
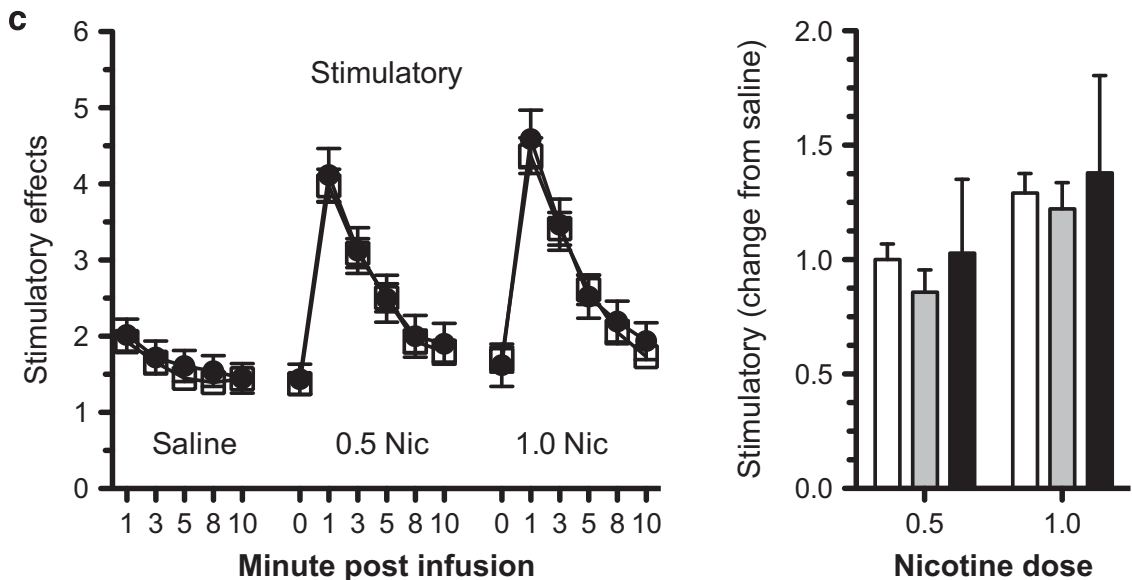

Figure I CHRNA5 rsI 6969968 moderates the aversive effects of nicotine. The subjective aversive (a), pleasurable (b) and stimulatory (c) ratings of drug effects in response to doses of saline and nicotine for $r$ 1 6969968*G homozygotes $(n=133)$ and $r$ l 6969968*A carriers $(n=59)$. The adjacent bar graphs show the change in response to nicotine relative to saline for each drug effect and each genotype group (GG, $n=133 ; A G, n=53 ; A A, n=6)$. Mean values are presented $\left( \pm\right.$ SEM). $0.5 \mathrm{Nic}=0.5 \mathrm{mg}$ nicotine per $70 \mathrm{~kg}$ body weight and $1.0 \mathrm{Nic}=1.0 \mathrm{mg}$ nicotine per $70 \mathrm{~kg}$ body weight. $* * * *<5 \times 10^{-8}$ for the interaction of genotype with dose.

\section{Cognitive Test Performance}

Scores on the CPT, MPT, and Stroop Test were better at the end of the session relative to baseline for each genotype group (main effect for time point for CPT: $\mathrm{F}_{(1,176)}=74.8$, $P<0.01 ;$ MPT: $\mathrm{F}_{(1,176)}=54.1, P<0.01$; and Stroop Test:
$\left.\mathrm{F}_{(1,176)}=82.6, P<0.01\right)$. Subjects with the $\mathrm{rs} 16969968^{\star} \mathrm{A}$ allele showed greater improvement on the Stroop Test relative to rs $16969968^{\star} \mathrm{G}$ homozygotes (Figure 2; time pointby-group interaction: $\left.\mathrm{F}_{(1,176)}=8.11, P<0.01\right)$. This effect was consistent when the analysis model included the AA and AG genotype groups (coded additively) rather than A carrier, 
and when including smoking intensity (cigarettes smoked per day), nicotine metabolite ratio, and cotinine and 3-hydroxycotinin levels as covariates (time point-by-group interaction: $\left.\mathrm{F}_{(1,167)}=10.1, P<0.005\right)$. At the end of the session, the average Stroop Test score for the AA genotype group improved $45 \%$, whereas the AG genotype group score improved $31 \%$ and the GG genotype group score improved

Table I Subject rs 16969968 Genotype Counts

\begin{tabular}{|c|c|c|c|c|c|}
\hline & \multicolumn{3}{|c|}{$\begin{array}{c}\text { rsl6969968 } \\
\text { genotype count } \\
\text { (frequency) }\end{array}$} & \multirow[t]{2}{*}{$\begin{array}{c}\text { Minor } \\
\text { allele } \\
\text { frequency }\end{array}$} & \multirow[t]{2}{*}{$\begin{array}{c}\text { HWE } \\
\text { test }^{\text {a }} \\
P \text {-value }\end{array}$} \\
\hline & AA & AG & GG & & \\
\hline African American & I (0.0I) & $10(0.10)$ & $85(0.89)$ & 0.063 & 0.31 \\
\hline European American & $5(0.05)$ & $43(0.45)$ & $48(0.50)$ & 0.28 & 0.31 \\
\hline
\end{tabular}

${ }^{\mathrm{a} E x a c t}$ test for Hardy-Weinberg equilibrium.
$20 \%$. The score improvement for each cognitive test and each genotype group is shown in Supplementary Figure S2. Test score improvement did not differ by rs16969968 genotype for the CPT (time point-by-group interaction: $\mathrm{F}_{(1,176)}=$ $\left.1.5 \times 10^{-5}, P=0.90\right)$ or the MPT (time point-by-group interaction: $\left.F_{(1,176)}=2.26, P=0.14\right)$. There were no main effects of genotype for CPT, MPT, or the Stroop Test (main effect of genotype: $P>0.05$ ), including no significant differences at the overnight-abstinence baseline.

\section{Nicotine Withdrawal and the Urge to Smoke}

Nicotine withdrawal symptoms (MNWS total score), the urge to smoke for reward (BQSU factor 1), and the urge to smoke to reduce negative symptoms (BQSU factor 2) were lower at the end of the experimental session relative to overnight-abstinence baseline (main effect of time for MNWS: $\mathrm{F}_{(1,188)}=64.85, P<0.01$; BQSU factor $1: \mathrm{F}_{(1,184)}=$ 116.6, $P<0.01$; BQSU factor $\left.2: \mathrm{F}_{(1,184)}=66.6, P<0.01\right)$. Nicotine withdrawal and the urge to smoke tended to reduce more for $r s 16969968^{\star} \mathrm{A}$ carriers compared with GG

Table 2 Smoking-Related Characteristics of the Sample (Mean (SEM))

\begin{tabular}{|c|c|c|c|c|c|c|c|c|c|}
\hline & $\begin{array}{c}\text { Cigarettes } \\
\text { per day }\end{array}$ & FTND & $\begin{array}{l}\text { Estimated } \\
\text { pack years }\end{array}$ & $\begin{array}{l}\text { Longest } \\
\text { abstinence } \\
\text { (months) }\end{array}$ & $\begin{array}{l}\text { Age of } \\
\text { onset }\end{array}$ & $\begin{array}{l}\text { No. of quit } \\
\text { attempts }\end{array}$ & $\begin{array}{c}\text { Nicotine } \\
\text { (ng/ml) }\end{array}$ & $\begin{array}{l}\text { Cotinine } \\
(\mathrm{ng} / \mathrm{ml})\end{array}$ & NMR \\
\hline European American & $19.13(1.04)$ & $5.43(0.21)$ & $19.56(1.20)$ & $12.42(2.47)$ & I6.28 (0.49) & $5.96(1.32)$ & $2.29(0.29)$ & $162.10(10.69)$ & $0.44(0.02)$ \\
\hline \multicolumn{10}{|l|}{ rs/6969968 genotype ${ }^{a}$} \\
\hline $\mathrm{GG}(n=133)$ & $19.08(1.15)$ & $5.51(0.20)$ & $19.56(1.03)$ & $8.62(2.30)$ & $16.23(0.43)$ & $3.60(0.93)$ & $2.55(0.31)$ & $197.75(12.22)$ & $0.38(0.02)$ \\
\hline
\end{tabular}

Abbreviations: FTND, Fagerström Test for Nicotine Dependence; NMR, nicotine metabolite ratio.

aMean values did not differ by genotype $(P>0.05)$ for all categories adjusted for race, sex, and age with the adjusted means shown.

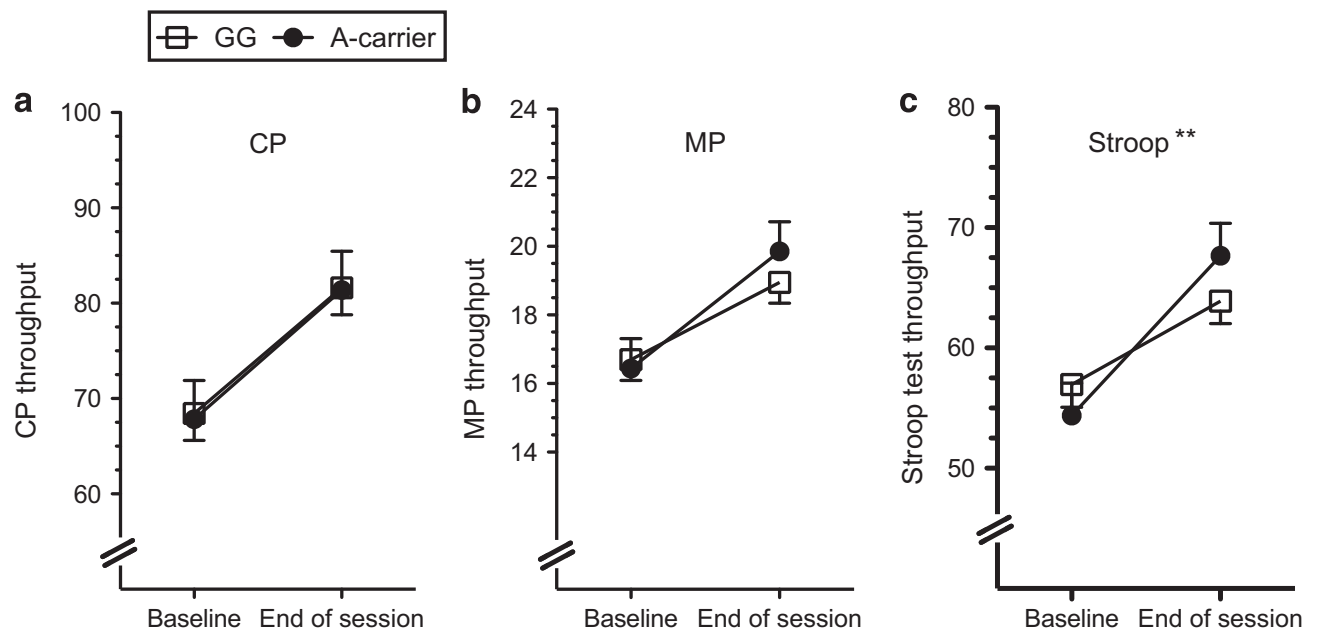

Figure 2 CHRNA5 rsI6969968*A carriers showed greater improvement in the Stroop Task. The throughput scores for (a) The Running Memory Continuous Performance Task (CP), (b) Mathematical Processing Task (MP), and (c) Stroop Task for rs $16969968 * G$ homozygotes and A carriers. Higher throughput scores indicate better performance, with possible scores ranging from 0 to 100 for all three tasks. The mean value adjusted for age, sex, and race is presented $( \pm$ SEM), and the interactive effect of genotype with time point (baseline vs end of session) is shown. Main effects of genotype were not significant $(P>0.3)$ for panels $a, b$ and $c$. ${ }^{*} * P<0.005$ for the interaction of genotype with time point. 
曰 GG $\bullet-$ A-carrier
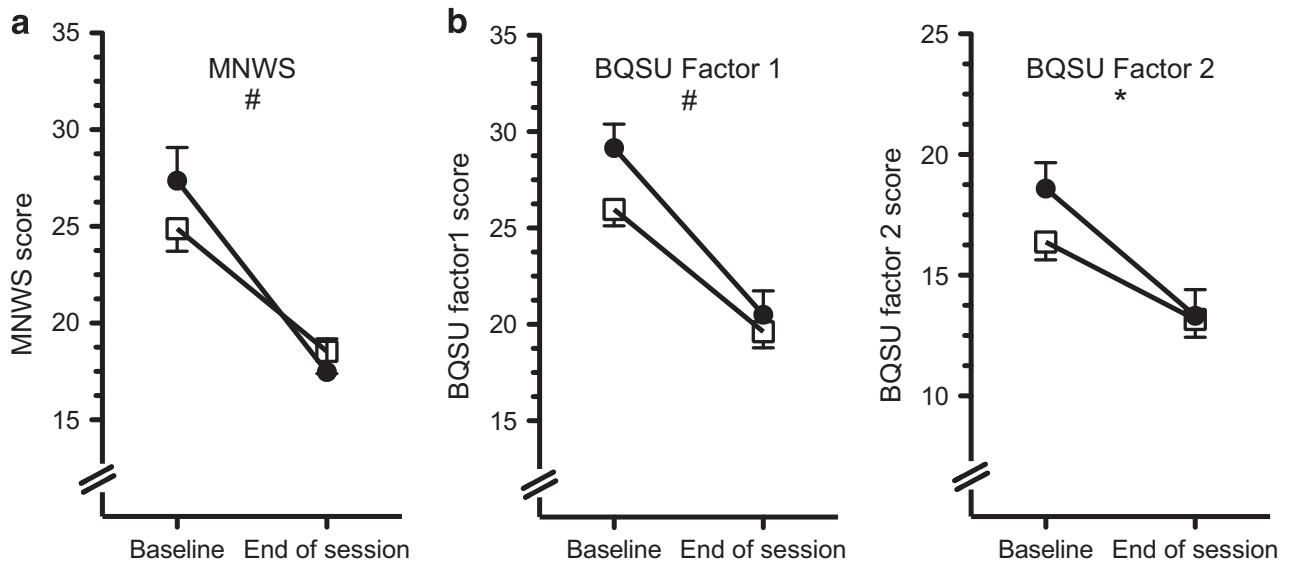

Figure 3 The association of rs 6969968 to nicotine withdrawal and the urge to smoke. (a) Minnesota Nicotine Withdrawal Scale (MNWS) scores and (b) Brief Questionnaire of Smoking Urges (BQSU) factor I (left) and factor 2 (right) scores, for rs I 6969968*G homozygotes and A carriers at baseline and at the end of the session. The mean value adjusted for age, sex, and race is presented ( \pm SEM), and the interactive effect of genotype with time point (baseline vs end of session) is shown. The main effect of genotype was not significant for panels a or $b$. ${ }^{*} P<0.05$ and ${ }^{\#} P<0.1$ for the interaction of genotype with time point.

homozygotes (Figure 3). These trend effects were consistent across measures (time point-by-group interactions for MNWS: $\mathrm{F}_{(1,188)}=3.13, P=0.079$; BQSU factor $1: \mathrm{F}_{(1,184)}=$ 2.78, $P=0.097$; QSU factor 2 : $\left(\mathrm{F}_{(1,184)}=3.95, P=0.048\right)$. There were no main effects of rs16969968 on the MNWS or BQSU (main effect of genotype: $P>0.05$ ), and there were no main or interactive associations of rs16969968 with the self-rated positive or negative affect, as measured by the PANAS $(P>0.05)$.

\section{The Acute Cardiac Response to Nicotine}

Nicotine increased $\mathrm{HR}$ and diastolic and systolic blood pressure (main effect of dose for $\mathrm{HR}$ : $\mathrm{F}_{(2,4096)}=994, P<0.01$; for diastolic blood pressure: $\mathrm{F}_{(2,4115)}=164.3, P<0.01$; for systolic blood pressure: $\left.\mathrm{F}_{(2,4144)}=224.9, P<0.01\right)$. The HR and blood pressure responses to nicotine did not differ for rs16969968 *A carriers compared with GG homozygotes (main effect of genotype: $P>0.05$; dose-by-genotype interaction: $P>0.05$; Supplementary Figure S3).

\section{DISCUSSION}

Variants in the CHRNA5-A3-B4 nicotinic receptor gene cluster are associated with ND, heavy smoking, and several consequent smoking-related health problems (Amos et al, 2008; Berrettini et al, 2008; Bierut et al, 2007; Bierut et al, 2008; Chen et al, 2012; Chen et al, 2009; Hansen et al, 2010; Hung et al, 2008; Li et al, 2010; Liu et al, 2010; Saccone et al, 2010; Saccone et al, 2007; Sarginson et al, 2011; Spitz et al, 2008; Thorgeirsson et al, 2008; Tobacco and Genetics Consortium, 2010; Wang et al, 2009). rs16969968 encodes an amino-acid substitution in CHRNA5 that might mediate some of these risk effects, and several lines of evidence support this hypothesis. A proposed risk mechanism, based largely on animal models, suggests that the CHRNA5 risk allele increases the heaviness of smoking by attenuating the aversive response to nicotine (Bailey et al, 2010; Bierut et al,
2008; Fowler et al, 2011; Fowler et al, 2013; Frahm et al, 2011; Jackson et al, 2010; Kuryatov et al, 2011; Saccone et al, 2010; Saccone et al, 2007; Tobacco and Genetics Consortium, 2010). However, this mechanism has not been directly examined in human studies. Here we sought to characterize how rs16969968 might differentially affect the acute response to nicotine in human subjects in the laboratory. We show that the allele associated with heavy smoking, rs $16969968^{\star} \mathrm{A}$ reduces the subjective aversive effects of nicotine delivered by IV injection. Although this was not the case in rs $16969968^{\star} \mathrm{A}$ carriers, nicotine evoked a pronounced aversive response in subjects who were homozygous for the smoking-protective allele, $\mathrm{rs} 16969968^{\star} \mathrm{G}$. We extended these findings by showing that $\mathrm{rs} 16969968^{\star} \mathrm{A}$ was also associated with greater improvement in cognitive test performance and consistently lower ratings of withdrawal and urge to smoke following the experimental session. These findings establish an important link between genetic association studies of heavy smoking and smoking-related disorder and the hypothesized risk mechanisms based on functional studies of rs16969968 and behavioral studies of $\alpha 5$ in rodents. Thus our observations support differential aversion to nicotine as a likely mechanism to explain the association of CHRNA5 rs16969968 with heavy smoking and disorders related to heavy smoking (Amos et al, 2008; Berrettini et al, 2008; Bierut et al, 2007; Bierut et al, 2008; Chen et al, 2012; Chen et al, 2009; Hansen et al, 2010; Hung et al, 2008; Li et al, 2010; Lips et al, 2010; Liu et al, 2010; Saccone et al, 2010; Saccone et al, 2007; Sarginson et al, 2011; Spitz et al, 2008; Thorgeirsson et al, 2008; Tobacco and Genetics Consortium, 2010; Wang et al, 2009).

The difference in ratings of aversive effects in response to nicotine for carriers of $\operatorname{rs} 16969968^{\star} \mathrm{A}$ relative to the GG homozygotes is striking, and the specificity of this effect relative to other outcomes is noteworthy. We observed no compelling difference based on rs16969968 for subject ratings of pleasurable effects or stimulatory effects and no differences in cardiovascular reactivity. These observations have several interesting parallels to studies of $\alpha 5$ function in 
rodents, most notably the essential role of $\alpha 5$ in mediating the aversive effects of nicotine (Bailey et al, 2010; Fowler et al, 2011; Frahm et al, 2011; Jackson et al, 2010). The attenuated aversive response to nicotine might reduce the reward-inhibiting and increase the reward-enhancing potential of the drug (Fowler et al, 2011; Fowler et al, 2013). The lower ratings of aversive effects for A carriers in the nicotine condition relative to the saline condition may relate, partly, to an alleviation of nicotine withdrawal, as shown by the change in BQSU and MNWS scores following nicotine infusion. An experiment conducted with non-abstinent smokers might help to uncouple these effects.

On a measure of selective attention and cognitive control (Stroop task), rs $16969968^{\star} \mathrm{A}$ carriers improved more from nicotine-abstinence baseline to end-of-session testing, after they had received nicotine, than GG homozygotes. We found no significant effect of rs16969968 on cognitive function at baseline while participants were in the nicotine-deprivation state (ie, following overnight-nicotine abstinence). Consistent with our baseline findings, a previous study showed no effect of rs16969968 on electrophysiological markers of cognitive control-related processes in nicotine-deprived regular smokers (Evans et al, 2014). CHRNA5 may function in several ways to affect risk for heavy smoking, including by modulating, cognitive function, and specifically the cognitive-enhancing effects of nicotine. The cognitiveenhancing effects of nicotine are an important component of the positive reinforcing effects that may contribute to the development and maintenance of smoking (Newhouse et al, 2004). Abstinence-induced differences in cognitive function might also contribute to the maintenance of smoking (Lerman et al, 2014). Hong et al (2010) showed that rs $16969968^{\star} \mathrm{A}$ was associated with weaker connectivity of a dorsal anterior cingulate-ventral striatal circuit and that the strength of this circuit was inversely correlated with ND severity. Consistent with additional roles for CHRNA5 beyond regulation of aversion to nicotine, Morel et al (2014) showed that $\alpha 5$ expressed in dopaminergic cells of the ventral tegmental area regulates sensitivity to nicotine. Combined, these studies indicate that CHRNA5 has some pleiotropic effects, beyond regulating aversion to nicotine, that warrant further investigation in relation to risk for heavy smoking.

The well-controlled IV nicotine paradigm was a strength of this study. With this paradigm, we could deliver precise dosing of nicotine to subjects who were biochemically confirmed to be abstinent and evaluate several outcomes that were potentially relevant to the functional effects of rs16969968. The size of the sample, adequate for both EAs and AAs, was also a strength, as we had sufficient power to demonstrate rs16969968 differences for subjective ratings of aversive effects in EA and AA subjects analyzed as separate groups.

Statistical power may have been insufficient to detect effects on some outcomes in the combined sample and in the EA and AA samples analyzed separately. The frequency of rs $16969968^{\star} \mathrm{A}$ is considerably higher in EA than in AA populations, and the statistical power to detect effects in the EA subset was far greater compared with the AA subset. There are racial differences, for example, differences in nicotine metabolism (Perez-Stable et al, 1998) that influence smoking behavior (Schoedel et al, 2004; Tyndale et al, 1999; Tyndale and Sellers, 2002). As such, some effects of rs16969968 may differ for EA compared with AA smokers on account of differences in nicotine metabolism. Our findings, negative and positive, should be viewed in light of these potential differences. Moreover, the Stroop Task and withdrawal effects (MNWS and BQSU) were modest relative to the effects on aversion, and these findings should be viewed as tentative.

Based on the work from several groups (Baker et al, 2009; Freathy et al, 2009; King et al, 2012; Munafo et al, 2011; Sarginson et al, 2011), including a recent meta-analysis of eight randomized clinical trials of smoking-cessation therapies (Bergen et al, 2013), CHRNA5-A3-B4 variants could be markers for smoking cessation and the response to cessation treatment. The meta-analysis of Bergen et al (2013) examined four nAChR SNPs, including rs1051730, which is in almost complete linkage disequilibrium with rs16969968 in European-ancestry populations. Bergen et al (2013) found that the minor allele of rs 1051730 (in phase with rs $16969968^{\star} \mathrm{A}$ ) was associated with high rates of abstinence with nicotine replacement therapy (NRT) and lower rates of abstinence with placebo treatment. The mechanisms for this differential treatment response have not been elucidated. Bergen et al (2013) suggested that the cognitive enhancing effects of nicotine could potentially mediate better NRT treatment outcomes for individuals with the CHRNA5 risk allele. Our findings also suggest that the attenuated aversive response to nicotine may help carriers of the CHRNA5 risk allele $\left(\mathrm{rs} 16969968^{\star} \mathrm{A}\right)$ better tolerate NRT. These possibilities need to be further examined in future studies.

In conclusion, we show that rs 16969968 has strong, statistically robust, and specific effects on the subjective response to nicotine. These effects may be significant from a translational perspective, and consideration of these effects may help to understand and optimize treatment outcomes, especially treatments based on CHRNA5-A3-B4 variants. Improving the response to smoking-cessation treatments could have significant health benefit, as quitting, especially at a young age, greatly reduces the mortality associated with smoking (Jha et al, 2013).

\section{FUNDING AND DISCLOSURE}

This research was supported by the Veterans Administration (VA) Mental Illness Research, Education and Clinical Center (MIRECC), the VA National Center for PTSD, and VA VISN1 Career Development Awards; NIH grants R03 DA027474, R01 AA017535, R01 DA030976, and R01 DA12690; and Army STARRS, which is sponsored by the Department of the Army and funded under cooperative agreement number U01MH087981 with the US Department of Health and Human Services, National Institutes of Health, National Institute of Mental Health (NIH/NIMH). Dr Sofuoglu has served as an expert witness on behalf of Pfizer in lawsuits related to varenicline. All other authors declare no competing financial interests.

\section{REFERENCES}

Amos CI, Wu X, Broderick P, Gorlov IP, Gu J, Eisen T et al (2008). Genome-wide association scan of tag SNPs identifies a susceptibility locus for lung cancer at 15q25.1. Nat Genet 40: 616-622. 
Bailey CD, De Biasi M, Fletcher PJ, Lambe EK (2010). The nicotinic acetylcholine receptor alpha5 subunit plays a key role in attention circuitry and accuracy. J Neurosci 30: 9241-9252.

Baker TB, Weiss RB, Bolt D, von Niederhausern A, Fiore MC, Dunn DM et al (2009). Human neuronal acetylcholine receptor A5-A3-B4 haplotypes are associated with multiple nicotine dependence phenotypes. Nicotine Tob Res 11: 785-796.

Bergen AW, Javitz HS, Krasnow R, Nishita D, Michel M, Conti DV et al (2013). Nicotinic acetylcholine receptor variation and response to smoking cessation therapies. Pharmacogenet Genomics 23: 94-103.

Berrettini W, Yuan X, Tozzi F, Song K, Francks C, Chilcoat H et al (2008). Alpha-5/alpha-3 nicotinic receptor subunit alleles increase risk for heavy smoking. Mol Psychiatry 13: 368-373.

Bierut LJ, Madden PA, Breslau N, Johnson EO, Hatsukami D, Pomerleau OF et al (2007). Novel genes identified in a highdensity genome wide association study for nicotine dependence. Hum Mol Genet 16: 24-35.

Bierut LJ, Stitzel JA, Wang JC, Hinrichs AL, Grucza RA, Xuei X et al (2008). Variants in nicotinic receptors and risk for nicotine dependence. Am J Psychiatry 165: 1163-1171.

Chen LS, Saccone NL, Culverhouse RC, Bracci PM, Chen CH, Dueker $\mathrm{N}$ et al (2012). Smoking and genetic risk variation across populations of European, Asian, and African American ancestrya meta-analysis of chromosome 15q25. Genet Epidemiol 36: 340-351.

Chen X, Chen J, Williamson VS, An SS, Hettema JM, Aggen SH et al (2009). Variants in nicotinic acetylcholine receptors alpha5 and alpha3 increase risks to nicotine dependence. Am J Med Genet B Neuropsychiatr Genet 150B: 926-933.

Dempsey D, Tutka P, Jacob P, Allen F, Schoedel K, Tyndale RF et al (2004). Nicotine metabolite ratio as an index of cytochrome P450 2A6 metabolic activity. Clin Pharmacol Ther 76: 64-72.

DeVito EE, Herman AI, Waters AJ, Valentine GW, Sofuoglu M (2013). Subjective, physiological, and cognitive responses to intravenous nicotine: effects of sex and menstrual cycle phase. Neuropsychopharmacology 39: 1431-1440.

Evans DE, MacQueen DA, Jentink KG, Park JY, Lin HY, Drobes DJ (2014). CHRNA5 variants moderate the effect of nicotine deprivation on a neural index of cognitive control. Genes Brain Behav 13: 626-632.

First MB, Spitzer RL, Gibbon M, Williams JB (1996). Structured Clinical Interview for DSM-IV Axis I Disorders-Patient Edition. Biometrics Research Department, New York State Psychiatric Institution: New York.

Fowler CD, Lu Q, Johnson PM, Marks MJ, Kenny PJ (2011). Habenular alpha5 nicotinic receptor subunit signalling controls nicotine intake. Nature 471: 597-601.

Fowler CD, Tuesta L, Kenny PJ (2013). Role of alpha5* nicotinic acetylcholine receptors in the effects of acute and chronic nicotine treatment on brain reward function in mice. Psychopharmacology (Berl) 229: 503-513.

Frahm S, Slimak MA, Ferrarese L, Santos-Torres J, Antolin-Fontes B, Auer $S$ et al (2011). Aversion to nicotine is regulated by the balanced activity of beta4 and alpha5 nicotinic receptor subunits in the medial habenula. Neuron 70: 522-535.

Freathy RM, Ring SM, Shields B, Galobardes B, Knight B, Weedon MN et al (2009). A common genetic variant in the 15q24 nicotinic acetylcholine receptor gene cluster (CHRNA5CHRNA3-CHRNB4) is associated with a reduced ability of women to quit smoking in pregnancy. Hum Mol Genet 18: 2922-2927.

Gelernter J KH, Sherva R, Almasy L, Herman AI, Koesterer R, Zhao $\mathrm{H}$ et al (2015). Genomewide association study of nicotine dependence in American populations: identification of novel risk loci in both African- and European-Americans. Biol Psychiatry 77: 493-503.
Hansen HM, Xiao Y, Rice T, Bracci PM, Wrensch MR, Sison JD et al (2010). Fine mapping of chromosome 15q25.1 lung cancer susceptibility in African-Americans. Hum Mol Genet 19: 3652-3661.

Hatsukami DK, Benowitz NL, Rennard SI, Oncken C, Hecht SS (2006). Biomarkers to assess the utility of potential reduced exposure tobacco products. Nicotine Tob Res 8: 169-191.

Herman AI, Jatlow PI, Gelernter J, Listman JB, Sofuoglu M (2013). COMT Val158Met modulates subjective responses to intravenous nicotine and cognitive performance in abstinent smokers. Pharmacogenomics J 13: 490-497.

Hoffmann D, Wynder EL (1986). Chemical constituents and bioactivity of tobacco smoke. IARC Sci Publ 74: 145-165.

Hong LE, Hodgkinson CA, Yang YH, Sampath H, Ross TJ, Buchholz B et al (2010). A genetically modulated, intrinsic cingulate circuit supports human nicotine addiction. Proc Natl Acad Sci USA 107: 13509-13514.

Hughes JR, Hatsukami D (1986). Signs and symptoms of tobacco withdrawal. Arch Gen Psychiatry 43: 289-294.

Hung RJ, McKay JD, Gaborieau V, Boffetta P, Hashibe M, Zaridze D et al (2008). A susceptibility locus for lung cancer maps to nicotinic acetylcholine receptor subunit genes on $15 \mathrm{q} 25$. Nature 452: 633-637.

Jackson KJ, Marks MJ, Vann RE, Chen X, Gamage TF, Warner JA et al (2010). Role of alpha5 nicotinic acetylcholine receptors in pharmacological and behavioral effects of nicotine in mice. J Pharmacol Exp Ther 334: 137-146.

Jensen KP, Herman AI, Morean ME, Kranzler HR, Gelernter J, Sofuoglu M et al (2014). FKBP5 variation is associated with the acute and chronic effects of nicotine. Pharmacogenomics $J$ (e-pub ahead of print 23 December 2014; doi:10.1038/tpj.2014.76).

Jha P, Ramasundarahettige C, Landsman V, Rostron B, Thun M, Anderson RN et al (2013). 21st-century hazards of smoking and benefits of cessation in the United States. $N$ Engl J Med 368: 341-350.

King DP, Paciga S, Pickering E, Benowitz NL, Bierut LJ, Conti DV et al (2012). Smoking cessation pharmacogenetics: analysis of varenicline and bupropion in placebo-controlled clinical trials. Neuropsychopharmacology 37: 641-650.

Kuryatov A, Berrettini W, Lindstrom J (2011). Acetylcholine receptor (AChR) alpha5 subunit variant associated with risk for nicotine dependence and lung cancer reduces (alpha4beta2)(2) alpha5 AChR function. Mol Pharmacol 79: 119-125.

Lerman C, Gu H, Loughead J, Ruparel K, Yang Y, Stein EA (2014). Large-scale brain network coupling predicts acute nicotine abstinence effects on craving and cognitive function. JAMA Psychiatry 71: 523-530.

Li MD, Cheng R, Ma JZ, Swan GE (2003). A meta-analysis of estimated genetic and environmental effects on smoking behavior in male and female adult twins. Addiction 98: 23-31.

Li MD, Yoon D, Lee JY, Han BG, Niu T, Payne TJ et al (2010). Associations of variants in CHRNA5/A3/B4 gene cluster with smoking behaviors in a Korean population. PLoS One 5: e12183.

Lips EH, Gaborieau V, McKay JD, Chabrier A, Hung RJ, Boffetta P et al (2010). Association between a $15 \mathrm{q} 25$ gene variant, smoking quantity and tobacco-related cancers among 17000 individuals. Int J Epidemiol 39: 563-577.

Liu JZ, Tozzi F, Waterworth DM, Pillai SG, Muglia P, Middleton L et al (2010). Meta-analysis and imputation refines the association of $15 \mathrm{q} 25$ with smoking quantity. Nat Genet 42: 436-440.

Morean ME, de Wit H, King AC, Sofuoglu M, Rueger SY, O'Malley SS (2013). The drug effects questionnaire: psychometric support across three drug types. Psychopharmacology (Berl) 227: 177-192.

Morel C, Fattore L, Pons S, Hay YA, Marti F, Lambolez B et al (2014). Nicotine consumption is regulated by a human polymorphism in dopamine neurons. Mol Psychiatry 19: 930-936. 
Munafo MR, Johnstone EC, Walther D, Uhl GR, Murphy MF, Aveyard P (2011). CHRNA3 rs1051730 genotype and short-term smoking cessation. Nicotine Tob Res 13: 982-988.

Newhouse PA, Potter A, Singh A (2004). Effects of nicotinic stimulation on cognitive performance. Curr Opin Pharmacol 4: $36-46$.

Perez-Stable EJ, Herrera B, Jacob P 3rd, Benowitz NL (1998). Nicotine metabolism and intake in black and white smokers. JAMA 280: 152-156.

Perkins KA (1996). Sex differences in nicotine versus nonnicotine reinforcement as determinants of tobacco smoking. Exp Clin Psychopharm 4: 166-177.

Reeves DL, Winter KP, Bleiberg J, Kane RL (2007). ANAM (R) genogram: historical perspectives, description, and current endeavors. Arch Clin Neuropsych 22: S15-S37.

Saccone NL, Culverhouse RC, Schwantes-An TH, Cannon DS, Chen X, Cichon S et al (2010). Multiple independent loci at chromosome 15q25.1 affect smoking quantity: a meta-analysis and comparison with lung cancer and COPD. PLoS Genet 6: 8.

Saccone SF, Hinrichs AL, Saccone NL, Chase GA, Konvicka K, Madden PA et al (2007). Cholinergic nicotinic receptor genes implicated in a nicotine dependence association study targeting 348 candidate genes with 3713 SNPs. Hum Mol Genet 16: 36-49.

Sarginson JE, Killen JD, Lazzeroni LC, Fortmann SP, Ryan HS, Schatzberg AF et al (2011). Markers in the 15q24 nicotinic receptor subunit gene cluster (CHRNA5-A3-B4) predict severity of nicotine addiction and response to smoking cessation therapy. Am J Med Genet B Neuropsychiatr Genet 156B: 275-284.

Schneider NG, Terrace S, Koury MA, Patel S, Vaghaiwalla B, Pendergrass $\mathrm{R}$ et al (2005). Comparison of three nicotine treatments: initial reactions and preferences with guided use. Psychopharmacology (Berl) 182: 545-550.

Schoedel KA, Hoffmann EB, Rao Y, Sellers EM, Tyndale RF (2004). Ethnic variation in CYP2A6 and association of genetically slow nicotine metabolism and smoking in adult Caucasians. Pharmacogenetics 14: 615-626.

Schuh KJ, Schuh LM, Henningfield JE, Stitzer ML (1997). Nicotine nasal spray and vapor inhaler: abuse liability assessment. Psychopharmacology (Berl) 130: 352-361.

Sherva R, Kranzler HR, Yu Y, Logue MW, Poling J, Arias AJ et al (2010). Variation in nicotinic acetylcholine receptor genes is associated with multiple substance dependence phenotypes. Neuropsychopharmacology 35: 1921-1931.

Sofuoglu M, Babb D, Hatsukami DK (2003). Labetalol treatment enhances the attenuation of tobacco withdrawal symptoms by nicotine in abstinent smokers. Nicotine Tob Res 5: 947-953.

Sofuoglu M, Herman AI, Nadim H, Jatlow P (2012). Rapid nicotine clearance is associated with greater reward and heart rate increases from intravenous nicotine. Neuropsychopharmacology 37: 1509-1516.

Sofuoglu M, Mouratidis M, Yoo S, Culligan K, Kosten T (2005). Effects of tiagabine in combination with intravenous nicotine in overnight abstinent smokers. Psychopharmacology (Berl) 181: 504-510.

Sofuoglu M, Poling J, Mouratidis M, Kosten T (2006). Effects of topiramate in combination with intravenous nicotine in overnight abstinent smokers. Psychopharmacology (Berl) 184: 645-651.

Sofuoglu M, Yoo S, Hill KP, Mooney M (2008). Self-administration of intravenous nicotine in male and female cigarette smokers. Neuropsychopharmacology 33: 715-720.

Spitz MR, Amos CI, Dong Q, Lin J, Wu X (2008). The CHRNA5-A3 region on chromosome $15 \mathrm{q} 24-25.1$ is a risk factor both for nicotine dependence and for lung cancer. J Natl Cancer Inst 100: $1552-1556$

Tammimaki A, Herder P, Li P, Esch C, Laughlin JR, Akk G et al (2012). Impact of human D398N single nucleotide polymorphism on intracellular calcium response mediated by alpha3beta4alpha5 nicotinic acetylcholine receptors. Neuropharmacology 63: 1002-1011.

Thorgeirsson TE, Geller F, Sulem P, Rafnar T, Wiste A, Magnusson KP et al (2008). A variant associated with nicotine dependence, lung cancer and peripheral arterial disease. Nature 452: 638-642.

Tiffany ST, Drobes DJ (1991). The development and initial validation of a questionnaire on smoking urges. $\mathrm{Br} J$ Addict 86: 1467-1476.

Tobacco and Genetics Consortium (2010). Genome-wide metaanalyses identify multiple loci associated with smoking behavior. Nat Genet 42: 441-447.

Tyndale RF, Pianezza ML, Sellers EM (1999). A common genetic defect in nicotine metabolism decreases risk for dependence and lowers cigarette consumption. Nicotine Tob Res 1(Suppl 2): S63-S67; discussion S69-70.

Tyndale RF, Sellers EM (2002). Genetic variation in CYP2A6mediated nicotine metabolism alters smoking behavior. Ther Drug Monit 24: 163-171.

Wang JC, Cruchaga C, Saccone NL, Bertelsen S, Liu P, Budde JP et al (2009). Risk for nicotine dependence and lung cancer is conferred by mRNA expression levels and amino acid change in CHRNA5. Hum Mol Genet 18: 3125-3135.

Watson D, Clark LA, Tellegen A (1988). Development and validation of brief measures of positive and negative affect: the PANAS scales. J Pers Soc Psychol 54: 1063-1070.

Yang BZ, Zhao H, Kranzler HR, Gelernter J (2005). Practical population group assignment with selected informative markers: characteristics and properties of Bayesian clustering via STRUCTURE. Genet Epidemiol 28: 302-312.

Supplementary Information accompanies the paper on the Neuropsychopharmacology website (http://www.nature.com/npp) 